\title{
Disseminação do ódio nas mídias sociais: análise da atuação do social media
}

Dissemination of hate on social media: analysis of social medias's performance Hate diffuser les médias sociaux: analyse des medias de l'action sociale

La difusión del odio en medios de comunicación social: análisis de los medios de social media

\author{
Marluci Stein ${ }^{1}$ \\ Cristine Hermann Nodari ${ }^{2}$ \\ Julice Salvagni ${ }^{3}$
}

Recebido em 22/03/2017; revisado e aprovado em 12/06/2017; aceito em 21/06/2017

DOI: http://dx.doi.org/10.20435/inter.v19i1.1535

\begin{abstract}
Resumo: Neste artigo, aborda-se a disseminação do ódio nas mídias sociais sob o ponto de vista de quem gerencia as plataformas na web. Em um estudo de caso com entrevista semiestruturada de sete profissionais, analisou-se como os responsáveis por administrar páginas na internet agem diante de comentários negativos que incitem o ódio. Os resultados apontaram conteúdos mais suscetíveis e o desconhecimento dos profissionais quanto a regras específicas na hora de interagir com haters e usuários.
\end{abstract}

Palavras-chave: mídias sociais; ódio; internet; cibercultura; interatividade.

Abstract: It addresses the spread of hate in social media from the point of view of who manages the platforms on the web. In a case study with a semi-structured interview of seven professionals, it was analyzed how those responsible for administering web pages act in the face of negative comments that incite hatred. The results pointed to more susceptible contents and the lack of knowledge of the professionals regarding specific rules when it comes to interacting with haters and users.

Keywords: social media; hate; internet; cyberculture; interactivity.

Résumé: Il traite de la propagation de la haine dans les médias sociaux du point de vue de qui gère les platesformes sur le Web. Dans une étude de cas avec entrevue semi-structurée sept professionnels analysé la façon dont les responsables de la gestion des pages Web agissent avant les commentaires négatifs qui incitent à la haine. Les résultats ont montré un contenu plus sensible et le manque de professionnels pour des règles spécifiques afin d'interagir avec les utilisateurs et les ennemis.

Mots-clés: médias sociaux; la haine; internet; cyberculture; interactivité.

Resumen: Se ocupa de la propagación del odio en los medios sociales desde el punto de vista de quién gestiona las plataformas en la web. En un estudio de caso con entrevista semiestructurada siete profesionales analizaron cómo los responsables de la gestión de páginas Web actuar antes de que los comentarios negativos que incitan al odio. Los resultados mostraron más contenido susceptible y la falta de profesionales para las reglas específicas con el fin de interactuar con los usuarios y los enemigos.

Palabras clave: medios de comunicación social; el ódio; internet; cibercultura; la interactividad.

\footnotetext{
${ }^{1}$ Centro Universitário Ritter dos Reis (UniRitter), Porto Alegre, Rio Grande do Sul, Brasil.

2 Feevale, Novo Hamburgo, Rio Grande do Sul, Brasil.

3 Universidade do Vale do Rio dos Sinos (Unisinos), São Leopoldo, Rio Grande do Sul, Brasil.
} 


\section{INTRODUÇÃO}

O drama da internet é que ela promoveu o idiota da aldeia a portador da verdade. (UMBERTO ECO, 2015)

Os sites de redes sociais tornaram-se cada vez mais presentes nas estratégias de comunicação e marketing das empresas e governos. Contudo, ao mesmo tempo em que as redes sociais tornaram-se grandes aliadas na hora de a corporação relacionar-se com seus stakeholders ${ }^{5}$, a instantaneidade com que comentários positivos e negativos chegam até a plataforma desafia a quem administra as páginas de Facebook e de outras mídias sociais.

Tendo em vista que o tema proposto neste artigo é relativamente novo, este estudo também se propõe a contribuir com os profissionais do mercado de comunicação e marketing, auxiliando-os na tarefa de gerenciar páginas de empresas, corporações e governos. Assim sendo, esta pesquisa buscou entender quais são as reações de quem administra as páginas das organizações, a fim de auxiliar outros social medias a lidar com situações que poderão transformar-se em uma crise para a imagem da organização, uma vez que esta pode passar a ser palco para a promoção do ócio, de ameaças ou mesmo de crimes de racismo ou discriminação. Além disso, convém lembrar que muitos casos de interação entre empresas e usuários nas redes sociais rendem uma repercussão positiva fora da rede e auxiliam na conquista de novos fãs e/ou admiradores. Por outro lado, uma má interação pode se tornar uma nota de esclarecimento pedindo desculpas aos usuários.

De acordo com Recuero (2009), uma Rede Social é composta por atores (pessoas ou grupos) e conexões (a interação entre os atores). Segundo a autora, o surgimento da Internet auxiliou as pessoas a difundirem as informações de forma mais rápida e mais interativa. Tal mudança "criou novos canais e, ao mesmo tempo, uma pluralidade de novas informações circulando nos grupos sociais" (RECUERO, 2009, p. 116).

Teixeira (2013) enfatiza a assertiva de que as redes sociais tornaram-se um veículo no qual diferentes pessoas, em qualquer lugar, de qualquer especialidade, têm a chance de participar e se engajar. As crises nas redes sociais, por exemplo, não são muito diferentes das crises que são repercutidas na imprensa. A autora também afirma que elas seguem a mesma lógica e que, por muitas vezes, os meios de comunicação se pautam pelos assuntos relevantes e debatidos dentro do ambiente online. Assim, as redes sociais "ajudam a disseminar a informação para além daquele grupo cativo de leitores de determinado jornal" (TEIXEIRA, 2013, p. 41).

Seguindo esse pressuposto que destaca que as mídias sociais tornaram-se um novo veículo de comunicação, convém ressaltar que a credibilidade de quem passa a informação é tão importante quanto o que está sendo disseminado. É neste campo que Solove (2007) afirma que a reputação está diretamente ligada à confiança. De acordo com o autor, com a constante exposição do cotidiano na internet, a quantidade de informações pessoais na web se torna cada vez maior e mais acessível, o que deixa a reputação de pessoas e organizações exposta e vulnerável.

\footnotetext{
${ }^{4}$ Declaração proferida durante evento na Universidade de Turim, no norte da Itália, em 2015. Disponível em:<http:// veja.abril.com.br/noticia/brasil/a-conspiracao-dos-imbecis>. Acesso em: 15 abr. 2016.

${ }^{5}$ Stakeholders são indivíduos e grupos que também têm um interesse nas consequências das decisões das organizações e podem influenciá-las. Incluem tanto clientes como concorrentes e devem ser tratados lealmente. Incluem também proprietários, fornecedores, financiadores, órgãos governamentais, grupos de pressão, funcionários, comunidades locais e a sociedade em geral (CHURCHILL, 2000, p. 13).
} 
Ao longo do trabalho buscou-se responder ao problema da pesquisa: Como empresas e organizações agem diante de comentários negativos que incitam o ódio nas páginas em que administram? Nesse sentido, a pesquisa tem como objetivo geral analisar como os responsáveis por administrar páginas de marcas e corporações agem diante de comentários, primordialmente, negativos e que incitam o ódio nas mídias sociais. Além disso, de forma específica, buscou-se identificar a frequência com que os comentários negativos aparecem nas páginas dos administradores entrevistados e, por fim, tentar identificar, com base nas teorias apresentadas, se as atitudes tomadas por eles diante de tais comentários são as mais corretas.

\section{REFERENCIAL TEÓRICO}

\subsection{O surgimento das redes sociais: um espaço virtual aos discursos de ódio}

De acordo com Castells (2012), a primeira rede de computadores, chamada ARPANET, entrou em funcionamento em 1 을 de setembro de 1969. A rede estava aberta aos centros de pesquisa que colaboravam com o Departamento de Defesa dos EUA, contudo os cientistas começaram a utilizá-la também para se comunicar entre os entusiastas da ficção científica. Depois do surgimento da ARPANET, que encerrou as atividades em 1990, outras redes foram sendo criadas, até chegar à internet que é conhecida atualmente. Em 1991 teve origem a Word Wide Web (WWW), a partir da união de estudos de internet e hipermídia (LEÃO, 2001).

Apesar do advento da internet, de acordo com Gosciola (2003), em 1990, apenas 38\% das casas norte-americanas possuíam conexão. A partir da comercialização e popularização, esses números foram crescendo, de acordo com o autor. Em 1995, 44 milhões de pessoas utilizavam a Internet. Três anos depois, os números haviam triplicado e chegado a 142 milhões de usuários. Um ano depois, os usuários somavam 259 milhões. De acordo com dados da União Internacional das Telecomunicações, órgão ligado à Organização das Nações Unidas (ONU) o mundo, em 2015, chegou a 3,2 bilhões de usuários, cerca de $40 \%$ da população mundial.

Segundo Primo (2007), a Web 2.0 é a segunda geração de serviços online e caracteriza-se por potencializar as formas de publicação, compartilhamento e organização de informações, além de ampliar os espaços para a interação entre os participantes do processo. A terceira geração da internet surge com a Web 3.0, também chamada de web semântica, em que a interação entre computadores e pessoas é maior. Essa evolução da internet permitiu aos usuários um crescimento no que se refere à participação e ao conteúdo gerado pelo próprio usuário. Castells (2007) define interatividade como a capacidade de o utilizador manipular e influenciar diretamente a experiência com o media, e de comunicar com outros através desse mesmo media. Já de acordo com Jenkins (2009), a interatividade refere-se ao modo como as novas tecnologias foram criadas para responder ao feedback do consumidor.

Recuero (2009) colabora ressaltando que o advento da Internet trouxe diversas mudanças para a sociedade, sendo a possibilidade de expressão e sociabilização por meio das ferramentas de comunicação mediadas pelo computador a mais significativa. Assim como a internet, as redes sociais também estiveram nesse processo de evolução em que os atores (pessoas, instituições ou grupos; os nós da rede) e as suas conexões (interações ou laços sociais) são o que definem uma rede social (RECUERDO, 2009).

Seguindo a mesma ideia, Marteleto (2001, p. 72), ressalta que as redes sociais representam "um conjunto de participantes autônomos, unindo ideias e recursos em torno de valores e interesses 
compartilhados". Conforme Pereira (2011), o IBOPE Nielsen Online publicou, em 2010, um estudo em que o Brasil aparece como o país mais conectado em redes sociais, com a participação de até $86 \%$ dos usuários ativos. Segundo o autor, a afinidade é o principal motivo que leva as pessoas a se unirem nas mídias sociais no Brasil, onde esta aproximação dá-se por diversos motivos, que vão desde opiniões pessoais a tipos bem específicos de comportamentos.

Recuero (2009) destaca que os sites de redes sociais foram definidos como sistemas que permitem a construção de uma persona através de um perfil ou página pessoal e também como a interação através de comentários e a exposição pública da rede social de cada ator. Nessa categoria, os espaços virtuais "possuem mecanismos de individualização e mostram as redes sociais de cada ator de forma pública e possibilitam que os mesmos construam interações nesses sistemas" (RECUERO, 2009, p. 103).

Teixeira (2013) por sua vez, ressalta que é necessário também entender a diferença entre mídias sociais e redes sociais. Segundo ela, mídias sociais é o termo mais abrangente para referir-se a todas as ferramentas com interatividade e da geração de conteúdo por meio de novas mídias. As redes sociais estão dentro desse cenário e constituem um tipo de mídia social. As redes sociais existem desde sempre e "são formadas por um agrupamento de pessoas ou organizações, que se unem com o objetivo em comum de estabelecer relacionamento e debater assuntos de interesse" (TEIXEIRA, 2013, p. 16). Neste trabalho utilizou-se como base de pesquisa o Facebook, já que as organizações têm utilizado o Facebook para aproximarem-se dos seus públicos e conquistar confiança na relação. Este é "um dos objetivos das redes sociais: criar aproximação com confiança e reciprocidade" (TEIXEIRA, 2013, p. 18). Contudo as redes sociais também têm servido como cenário relativamente anônimo que vem autorizando muitas pessoas a expressar o seu ódio frente aos mais diversos conteúdos publicados.

O comportamento dos usuários e suas interações com os ambientes virtuais apontam para a necessidade de uma revisão teórica que dialogue com as outras formas de conceber o espaço, que agora também é virtual, além de fazer relação com a sensação de anonimato presente nesses novos arranjos sociais. De acordo com Ostrower (1978), o comportamento de cada ser humano se molda pelos padrões culturais, do grupo em que ele, indivíduo, nasce e cresce. Vinculado a esses padrões coletivos, ele se desenvolverá enquanto indivíduo com seu modo pessoal de agir, seus sonhos, aspirações e realizações. Honneth (2003), por sua vez, destaca que os indivíduos e os grupos sociais somente podem formar a sua identidade quando forem reconhecidos intersubjetivamente e que esse reconhecimento ocorre em diferentes dimensões da vida: no âmbito privado do amor, nas relações jurídicas, e na esfera da solidariedade social. Essas três formas explicam a origem das tensões sociais e as motivações morais dos conflitos.

A maior parte dos sociólogos, conforme afirmam Degenne e Forsé (1994), admite que o comportamento e as opiniões dos indivíduos dependem das estruturas nas quais eles estão inseridos. Os autores (LATOUR, 2009; 2012) destacam que os indivíduos pertencem a categorias e a redes relacionais. Essas redes fornecem uma explicação do comportamento social baseada na interação entre os atores sociais. Convém ressaltar que essa interação também pode ser estudada do ponto de vista da internet (LEMOS, 2013). O virtual "em seu uso cotidiano, é definido com algo que existe, mas não materialmente" (MOCELLIM, 2009, p. 91). Contudo, para o mesmo autor, a existência desse espaço, mesmo que virtual, propôs a possibilidade de propiciar uma relação social independente da presença material. 
Assim, a interação social tem como instrumentos os símbolos, pois os grupos sociais se estruturam e interagem para estabelecer as normas e padrões comportamentais de determinada sociedade. O ódio, apresentado nesta pesquisa por meio de seu discurso, pode ser considerado como uma dessas simbologias. De acordo com Lebrun (2008), o ódio é oriundo da opressão. A civilização "impõe sempre um gozo a menos, uma falta, uma restrição e a isso respondemos como ódio" (LEBRUN, 2008, p. 9).

Comumente atrelado a situações de conflito, "o discurso de incitação do ódio tende a diminuir a autoestima das vítimas, impedindo assim a sua integral participação em várias atividades da sociedade civil, incluindo o debate público" (FISS, 2005, p. 47). Esse discurso de ódio pode acontecer tanto nos meios online quanto nos offline. Quando alguém dissemina o ódio ao falar mal de outros atores por meio de espaços de interação na internet, há a ação dos nominados de "haters", segundo Amaral e Monteiro (2013). Esses "odiadores", como são chamados, possuem acesso facilitado à internet e espalham o ódio em postagens de redes sociais ou sites da internet. Com o aumento desses discursos de ódio nas redes sociais, surge um problema social que intensifica a exposição de estigmas sociais (GOFFMANN, 2008), visto que, em muitos momentos, esses discursos estão repletos de preconceito e termos pejorativos.

Nesse sentido, Meyer-Pflug (2009, p. 97) conceitua o discurso do ódio manifestado através da internet como algo que "consiste na manifestação de ideias que incitam à discriminação racial, social ou religiosa em relação a determinados grupos, na maioria das vezes, as minorias". A autora ainda ressalta que esses discursos têm a finalidade deliberada de desqualificar e inferiorizar um grupo de pessoas, cuja dignidade se vê aviltada pelo emissor. Assim, surge o ódio como forma de expressão do indivíduo por meio da internet.

\subsection{Comportamento dos usuários nas redes sociais}

O advento e popularização das redes sociais têm transformado a forma como as pessoas se comunicam, seja entre amigos, seja entre marcas, corporações e figuras públicas. Há pouco tempo, para se fazer uma reclamação a respeito de determinado produto ou serviço, era necessário entrar em contato via telefone com o Serviço de Atendimento ao Cliente (SAC) da empresa. Atualmente, a instantaneidade com que isso acontece é cada vez maior. Em poucos minutos, uma reclamação atinge a rede e seus milhares de usuários. Recuero (2012) afirma que as redes sociais impactaram profundamente o cotidiano das pessoas, alterando a forma como se relacionam, constroem e percebem valores e mesmo como constroem significados e sentidos. Segundo ela, eles não apenas refletem essas redes, mas influenciam sua construção e, com isso, os fluxos de informação que circulam nesses grupos.

Além disso, da mesma forma que os sentimentos externados na vida real (offline), eles também são disseminados via redes sociais por meio de curtidas, comentários e/ou compartiIhamentos. Teixeira (2013) contribui dizendo que a tecnologia permitiu que as pessoas assumissem esse caráter mais participativo. "Elas presenciam um fato positivo ou negativo, registram e transmitem para outros, que dão seu posicionamento sobre aquela situação e aos poucos vão envolvendo outras situações" (TEIXEIRA, 2013, p. 17).

A interatividade, de acordo com Salaverría e Negredo (2008), pode ser apontada de quatro formas: conversacional (na qual acontece a maior parte dos comentários), de transmissão (meio de envio da mensagem), de consulta (a escolha acontece por meio de alternativas) e de registro (pela qual os meios de comunicação entendem e se adaptam aos usuários). 
Conforme Vasconcelos (2009), a internet auxiliou no desenvolvimento de consumidores mais exigentes que, antes de iniciarem o processo de compra, por exemplo, utilizam a web para verificar o histórico de reclamações contra a empresa, produto ou serviço que estejam interessados. É por esse motivo que diversos autores aconselham que as organizações trabalhem de forma contundente a opinião pública na internet. Teixeira (2013) orienta que as organizações abasteçam esse grupo com informações corretas e construídas de forma estratégica para que a mensagem chegue até os stakeholders. Tais ações "se transformam em créditos para quando surgir uma crise e que a empresa poderá usar para que sua marca não saia arranhada" (TEIXEIRA, 2013, p. 20).

Contudo, por mais que quem administre as redes sociais da empresa, organização ou figura pública e/ou celebridades tome todos os cuidados e faça o monitoramento necessário, muitas vezes a página pode ser vítima de um discurso de ódio ou de incitação à violência pelo conteúdo da postagem. De acordo com Dahlgren (2005), os usuários que incitam o ódio, normalmente, pertencem a um grupo (cibergrupo) que fomenta a intolerância e a hostilidade para com os outros e, ainda, remetem a práticas e discursos cotidianos.

Fenton (2012) argumenta que o uso da internet para fins de disseminação de ódio e violência dá voz e poder a quem não os possui nos meios tradicionais, permitindo, então, que as pessoas se unam em torno de causas para promover uma mudança social. Essas características "também se relacionam à natureza da política online, que é frequentemente associada com protesto, do que com a definição de projetos em longo prazo" (FENTON, 2012, p. 151).

$\mathrm{Na}$ internet também há uma lacuna para que informações não confiáveis cheguem até o público, seja de maneira planejada ou não - muitas vezes até com a segunda intenção de incitar a violência e o ódio. Eco (2015) reforça que o imediatismo com que as informações ganham o mundo, deixa a mídia tradicional para trás e ajuda a disseminar informações não verdadeiras nos meios disponíveis. Segundo ele, a "Internet pode ter tomado o lugar do mau jornalismo", pois é o local onde as pessoas não sabem diferenciar uma fonte credenciada de uma disparatada.

\section{METODOLOGIA}

Para atingir os objetivos propostos e responder ao problema deste artigo, optou-se por uma pesquisa de natureza exploratória com abordagem qualitativa que, de acordo com Erickson (1989), caracteriza-se pelo enfoque interpretativo. Gil (2006) reforça essa tese e salienta que a análise qualitativa depende de muitos fatores e que o processo pode ser definido como uma sequência de atividades que envolve a redução dos dados, a categorização desses dados, sua interpretação e a redação do relatório.

Por sua vez, a pesquisa de natureza exploratória, de acordo com Gil (2006), proporciona uma maior familiaridade com o problema, com vistas a torná-lo mais explícito ou a constituir hipóteses. $O$ autor ainda reforça que esse tipo de pesquisa tem por principal finalidade "desenvolver, esclarecer e modificar conceitos e ideias a partir da formulação de problemas mais precisos ou hipóteses pesquisáveis para estudos posteriores" (GIL, 2006, p. 43). Ele ainda destaca que ela é utilizada, em especial, quando o tema escolhido pelo pesquisador é pouco explorado, o que dificulta a formulação de hipóteses precisas.

A partir desse conceito, portanto, podemos perceber que, devido ao fato de a disseminação do ódio nas mídias sociais sob o ponto de vista de quem é responsável por administrá-la ter sido pouco explorado na forma de pesquisa, torna o tema passível de estudo. Por ser um método amplo e contar com diversas técnicas, para esta pesquisa, foi utilizado o Estudo de Caso, que, 
de acordo com Yin (2001), é a estratégia utilizada para se examinar acontecimentos contemporâneos dentro do contexto da vida real quando os limites entre o fenômeno e o contexto não estão claramente definidos. O autor ainda reforça que o método é a estratégia mais adequada para responder a questões do tipo "como" e "por que", em situações em que o pesquisador tem pouco controle sobre os eventos.

Entre os propósitos destacados por Gil (2006) para se utilizar o método de Estudo de Caso, está o de explorar situações da vida real cujos limites não estão claramente definidos; preservar o caráter unitário do objeto estudado; descrever a situação do contexto em que a investigação está sendo feita; formular hipóteses ou desenvolver teorias; e explicar as variáveis causais de determinado fenômeno em situações muito complexas que não possibilitam a utilização de levantamentos e experimentos.

Já a coleta de dados é realizada por meio de entrevistas semiestruturadas (GASKELL, 2003) com sete profissionais que atuam diariamente com mídias sociais no Brasil, seja de forma prática ou teórica. Sobre a entrevista, Gil (2006) a conceitua como uma das técnicas de coleta de dados mais utilizadas no âmbito das ciências sociais, visto que ela possibilita a obtenção de dados referentes aos mais diversos aspectos da vida social, e os dados são suscetíveis de classificação e de quantificação. A pesquisa documental feita com base em postagens de Facebook, "vale-se de materiais que não recebem ainda um tratamento analítico, ou que ainda podem ser reelaborados de acordo com os objetos da pesquisa" (GIL, 2006, p. 45).

A análise dos dados coletados por meio das entrevistas será feita a partir de análise de conteúdo que, de forma bastante simples, Creswell (2007) conceitua como uma técnica que consiste em extrair sentido dos dados de texto e imagem. Além disso, tem por objetivo, conforme afirma Chizzotti (2006), compreender o sentido das comunicações, seu conteúdo e significados explícitos ou ocultos.

Nesta pesquisa, como se pode ver a seguir, durante a análise de dados, seguiram-se os passos apresentados por Bardin (2006) para uma melhor organização e estruturação do trabaIho. A autora elenca três etapas da análise de conteúdo: i) a pré-análise, quando se organiza o material coletado, sistematizando as ideias iniciais; ii) a exploração do material, em que são feitas a codificação, a classificação e a categorização das informações para que se parta para a descrição analítica, e; iii) o tratamento dos resultados, inferência e interpretação, quando é realizada a condensação e o destaque das informações para análise, culminando na análise final.

\section{ANÁLISE DOS DADOS}

As redes sociais tornaram-se um espaço aberto para que as pessoas deem suas opiniões, sejam elas positivas, negativas ou neutras, a respeito de determinados assuntos, pessoas, marcas, instituições ou governos. Neste trabalho, buscou-se entender as reações de profissionais que atuam com mídias sociais diante dessas interações do público, em especial, as negativas que incitam o ódio e/ou a violência. Para isso, foram realizadas, entre os dias 17 de maio e 3 de junho de $2016^{6}$, sete entrevistas semiestruturadas com profissionais que estudam sobre interatividade e mídias sociais e também com quem diariamente trabalha como social media seja em agência de comunicação, empresa ou instituição.

\footnotetext{
${ }^{6}$ Período de relevante discussão política no Brasil, marcado especialmente pelo forjado processo de impedimento da continuidade do mandato de Dilma Rousseff como presidenta da República.
} 
Por terem sido convidados a falar de forma livre a respeito dos temas levantados na pesquisa, os sete entrevistados tiveram suas identidades preservadas e serão nominados como Entrevistado 1 (E1), Entrevistado 2 (E2), Entrevistado 3 (E3), Entrevistado 4 (E4), Entrevistado 5 (E5), Entrevistado 6 (E6) e Entrevistado 7 (E7), conforme perfis traçados abaixo.

Mestre em Comunicação e Mercado, E1 é jornalista, estudante de psicanálise com livros e artigos publicados voltados à comunicação organizacional e mídias sociais. Além disso, possui sociedade em uma empresa de comunicação, há onze anos no mercado nacional, que presta serviços de social media e assessoria de imprensa a grandes marcas. E2 também é jornalista com doutorado em Comunicação Social. Atua como docente na área de comunicação e social media há cinco anos e, em 2013, fundou uma empresa que presta serviços digitais.

Como integrantes do grupo técnico estão: E3 que é jornalista, com especialização em comunicação estratégica, que trabalha há três anos com mídias sociais na área de política nacional. E4 também é jornalista e coordena a parte de conteúdo em uma agência de comunicação presente em Porto Alegre e São Paulo, com foco em mídias digitais. Atua há seis anos com mídias sociais na área empresarial. Já E5 possui formação em publicidade e propaganda e tem como foco de trabalho as mídias sociais. Trabalha há quatro anos como social media na área empresarial e, atualmente, é analista de conteúdo em uma agência de mídias sociais com abrangência nacional. E6, por sua vez, atua na área comercial e de marketing há seis anos. É relações públicas e trabalha como gerente comercial em uma instituição de ensino focada na área jurídica. Atua também como responsável pela criação e administração dos perfis da instituição nas redes sociais. Para concluir, E7 tem formação em Publicidade e Propaganda e trabalha há dois anos como analista de mídias sociais na área de política estadual.

\subsection{A disseminação do ódio nas mídias sociais na visão dos entrevistados}

Diariamente o Facebook recebe cerca de 1 milhão de denúncias de conteúdo de ódio ou ilegal. Atentos a esses números cada vez mais crescentes, as plataformas Microsoft, Google, Twitter e Facebook assinaram no dia 31 de maio de $2016^{7}$ um documento elaborado pela União Europeia, que traz regras sobre conteúdos racistas, violentos e ilegais nas redes sociais. De acordo com o documento, o objetivo da união dessas empresas, que são dependentes de comentários de usuários para manter suas redes ativas, é criar uma colaboração entre as grandes companhias de redes sociais para que o conteúdo de ódio seja controlado com mais firmeza e rapidez.

Antes disso, em fevereiro de 2016, o Facebook já havia demonstrado sua preocupação com o tema ao lançar no Brasil a Central de Prevenção ao Bullying. A iniciativa foi criada pela rede social e, até então, estava já presente em mais de 50 países como Índia, Estados Unidos, México. A plataforma serve como apoio tanto para vítimas quanto para agressores e é mais um dos esforços da rede para combater a discriminação, discurso de ódio e bullying.

Ainda sobre o mapeamento dos discursos de ódio, o Ministério da Justiça do Brasil criou ${ }^{8}$, no final de 2014, um grupo de trabalho interministerial, em conjunto com a Polícia Federal, para

\footnotetext{
${ }^{7}$ Disponível em: <http://g1.globo.com/tecnologia/noticia/2016/05/facebook-microsoft-google-e-twitter-se-unempara-barrar-discurso-de-odio.html>. Acesso em: 28 abr. 2016.

${ }^{8}$ Disponível em: <http://www.justica.gov.br/noticias/governo-federal-ira-mapear-crimes-de-odio-na-internet> e $<$ http://agenciabrasil.ebc.com.br/direitos-humanos/noticia/2014-11/governo-cria-grupo-de-trabalho-para-mapearcrimes-de-odio-na>. Acesso em: 28 abr. 2016.
} 
monitorar e mapear crimes contra os direitos humanos nas mídias sociais. A tarefa principal do grupo é receber e analisar denúncias sobre páginas da internet que promovem o ódio e fazem apologia à violência e à discriminação. Tais números no Brasil são comprovados pela SaferNet Brasil $^{9}$, uma associação civil sem fins lucrativos que oferece um serviço de recebimento de denúncias anônimas de crimes e violações contra os Direitos Humanos na Internet. Em dez anos de existência a organização já recebeu e processou 3.746.062 denúncias anônimas envolvendo 628.848 páginas (URLs) distintas, das quais 201.066 foram removidas.

Diversos foram os relatos dos entrevistados quanto à utilização das redes sociais pelos indivíduos. De acordo com E2, as pessoas, nas redes sociais, não se dão conta de que elas não são anônimas e colocam exatamente o que pensam, independente do conteúdo ali inserido. E1, por sua vez, destaca de forma mais profunda que vê uma mudança de comportamento em relação ao uso das redes sociais nos últimos tempos. Para ela, é importante entender e saber que quem está atrás das máquinas e dos logins é um ser humano que pensa e age. "A grande diferença das redes sociais, hoje, é que nós temos espaço para mostrar o que pensamos, o que fazemos e como agimos. Esta para mim é a grande questão" (E1), sustenta.

E1 ainda ressalta que essas informações devem ser levadas em consideração na hora de se administrar uma página no Facebook. Para ela, é necessário entender com quem se está falando, qual a linguagem que deve ser utilizada pela marca, qual forma de comunicação será utilizada e, por fim, o que as pessoas que seguem a marca gostam. Segundo a entrevistada, é impossível falar/agradar todo mundo por isso o mais importante é encontrar uma forma de atingir a maioria sem perder tempo com quem não faz parte do público da marca/organização.

Corroborando, Teixeira (2011) destaca o quanto é importante enviar mensagens certas e adequadas, com coerência, com posicionamentos corretos para os públicos de acordo com os objetivos e valores da organização. Castells (2009) já ressaltava o quanto as pessoas, sete anos atrás, já estavam mais conectadas seja por laptops, smartphones, tabletes ou qualquer outro dispositivo de alta tecnologia que permita compartilhar experiências na internet. Dados colhidos pelo Facebook ${ }^{10}$ em dezembro de 2015 indicavam que 3,2 bilhões de pessoas estavam conectadas à internet no mundo, o que corresponde a $44 \%$ da população mundial, estimada em 7,3 bilhões. Em comparação com o mesmo estudo feito no final de 2014, houve crescimento de 200 milhões de pessoas.

Com todo esse universo de pessoas conectadas à internet, o número de incitações ao ódio nesse espaço também tem aumentado, conforme observação dos entrevistados nesta pesquisa. E3 considera que o atual momento político brasileiro tem feito os usuários posicionarem-se de forma bipolarizada (ou se é de um lado ou de outro). Segundo ela, a postura de que existem apenas dois lados e que se deve escolher entre um e outro tem ficado intrínseca no pensamento dos internautas. Ela ainda considera que as posturas mais intolerantes e que, por conseguinte, chegam ao ódio, devem-se muito à falta de meio termo nas opiniões, além da rápida disseminação da informação e a facilidade de emitir opiniões muitas vezes rasas. E4 lembra que, antigamente, não estávamos acostumados a ver tanta manifestação negativa e raivosa. Ela credita este aumento, principalmente, ao espaço aberto que as pessoas têm atualmente para se manifestar. "Dizer ao Facebook é como abrir uma janela e berrar para fora. Naturalmente, aliado a isso, também

9 Disponível em: <http://new.safernet.org.br/>. Acesso em: 28 abr. 2016.

${ }^{10}$ Disponível em: <http://newsroom.fb.com/news/2016/02/state-of-connectivity-2015-a-report-on-global-internetaccess/>. Acesso em: 3 jun. 2016. 
vem a falta de filtro e pudor para qualquer tipo de coisa, tanto para o bem, quanto para o mal", (E4) analisa.

E5 pondera que, apesar de raramente deparar-se com comentários de ódio nas páginas em que administra (por se tratarem de marcas ligadas aos setores infanto-juvenis), essas reações são comuns no meio, principalmente pela proteção que a internet oferece a esses usuários: "ninguém está me vendo, ninguém sabe onde me encontrar, por isso posso falar o que eu quiser", lembra.

Sobre as manifestações e interações nas mídias sociais, pode-se traçar um paralelo com a origem dos movimentos sociais que, segundo Castells (2013), são fonte de mudanças sociais e podem constituir uma nova sociedade com a ideia de Lebon (1895) que trazia o poder das multidões, seja ele para o bem ou para o mal. De acordo com Castells (2013, p. 7), "os movimentos espalharam-se por contágio num mundo ligado pela internet sem fio e caracterizado pela difusão rápida, viral, de imagens e ideias". Lebon (1895, p. 24), por sua vez, faz um paralelo entre os bons e maus sentimentos manifestados por uma multidão. Segundo ele, ambos apresentam a dupla característica de serem muito simples e muito exagerados, o que coloca as multidões ao abrigo da dúvida e da incerteza. O indivíduo em multidão "assemelha-se aos seres primitivos" (LEBON, 1895, p. 24). Ele ainda ressalta que uma suspeita levantada, logo se transforma em uma evidência indiscutível nas multidões já que todos os sentimentos nesse contexto são contagiosos. Lebon (1895) ainda complementa ao dizer que o imbecil, o ignorante e o invejoso libertam-se da nulidade e da impotência quando estão em multidão. Ainda destaca que tal exagero incide muitas vezes sobre os maus sentimentos, o que explicaria a facilidade com que as multidões são levadas aos piores excessos.

Em que pese às opiniões dos entrevistados desta pesquisa que destacaram que as redes sociais são consideradas um espaço livre para disseminação de opiniões, deve-se também ressaltar que tanto os discursos de ódio, quanto de violência devem ser analisados de forma mais rígida pelos sites de redes sociais, já que existe, hoje, uma sensação de impunidade por isso.

A prova de que os números de disseminação de ódio só aumentam na internet são os indicadores da Central Nacional de Denúncias de Crimes Cibernéticos (Safernet) já citados neste trabalho e que chegam a quase 4 milhões, em dez anos. Somente em 2015, o número chegou a 139.643 denúncias anônimas. Além disso, dos cinco entrevistados que fazem parte do grupo técnico desta pesquisa (do E3 ao E7), apenas E4 e E5 identificam com pouca frequência o surgimento de comentários que incitam o ódio e a violência nas páginas em que administram. Os demais entrevistados (E3, E6 e E7) identificam diariamente comentários que seguem essa linha. Segundo E7, o surgimento de comentários que incitam o ódio está diretamente ligado ao patrocínio de postagens, o que faz com que o conteúdo seja levado além do público/fãs da marca e/ ou organização. Nesse ponto, convém lembrar que, constantemente, o Facebook, por exemplo, tem alterado seu algoritmo que calcula quais publicações são relevantes para cada usuário. Dessa forma, um número cada vez mais restrito de publicações de marcas chega até os usuários. A opção, então, é pagar para se ter um alcance maior. seja nas publicações, seja nas páginas.

Após constatar a frequência com que os comentários de ódio chegam até as páginas de Facebook, é necessário identificar também quais temas poderão gerar polêmica e, por consequência, acabar por atingir a imagem da marca e/ou organização. A maioria dos entrevistados desta pesquisa identificou conteúdos que tratam de política, religião, animais, gêneros e raça como mais suscetíveis a receberem comentários que incitem ódio. E3 lembra que toda página que manifesta preferências ou opiniões está propensa a receber esse tipo de comentários. E4, 
por sua vez, colabora e ressalta que, atualmente, muitos temas sensíveis acabam virando bandeiras da população como respeito de gênero, raça, política. "Esses são terrenos sempre muito sensiveis. Onde a marca entrar em algum desses conteúdos, ela está sujeita a receber critica do grupo que é contra aquilo que se está posicionando" (E4), complementa.

Ou seja, temas que são sensíveis no mundo offline, tornam-se assim ainda mais quando tratados na web. Nesse sentindo, Castells (2013) aponta que "embora os movimentos tenham em geral sua base no espaço urbano, mediante ocupações e manifestações de rua, sua existência contínua tem lugar no espaço livre da internet". Também nesse sentido, Wolton (2010, p. 34) afirma que a internet dá voz aos usuários que, por sua vez, mobilizam-se e reivindicam sempre que necessário. $\mathrm{O}$ autor ainda declara que a internet está adaptada à globalização caso não tenha de ser a única ferramenta das lutas pela emancipação. Além disso, a repressão, a desinformação e a manipulação podem ser acentuadas caso os poderes autoritários e ditatoriais sirvam-se da internet (WOLTON, 2010). Malini e Antoun (2013) tratam também, de forma discreta, a respeito do discurso de ódio na internet, identificando-os como usuários que perpassam os limites da liberdade de expressão.

\subsection{As reações dos profissionais diante de comentários que incitam ódio}

Busca-se entender as reações de quem administra páginas nas redes sociais diante de comentários que incitam o ódio, a fim de auxiliar profissionais a lidar com situações que poderão transformar-se em uma crise de imagem para a organização. A exclusão de comentários é o tema mais polêmico entre os entrevistados. E3 diz que a primeira reação diante de um comentário de ódio é a exclusão e caso o usuário retorne a disseminar, a opção é bani-lo: "Se o usuário usar palavras de baixo calão, incitar ódio e violência, terá seu comentário deletado e avisado do porquê foi" (E3).

Já E2 ressalta que, do ponto de vista teórico, a reação que não deve ser considerada em primeiro lugar é a de excluir os comentários: "No momento que a pessoa deletar um comentário em um espaço que é livre, ela está privando os outros que darem a opinião delas". E2 ainda complementa dizendo que dependendo do tipo de caso ou de página, deve ser trabalhada uma gestão de crises mesmo, seja para responder diretamente para as pessoas ou trabalhar em outros tipos de posts para que as pessoas possam compreender melhor sobre aquele assunto. "Mas nunca deletar", decreta.

Os demais entrevistados dividem-se entre responder o comentário ou ignorá-lo e deixar o hater sem resposta. De acordo com E5, a primeira orientação para as páginas em que administra é a de deixar sem resposta, porém, caso o comentário viole as normas de conduta da página, ele pode, sim, ser deletado.

É preciso analisar com que intenção o comentário foi posto ali. Se estiver apresentado como uma opinião, o ideal é deixar que os próprios fãs reprimam o usuário. Caso o comentário esteja relacionado diretamente à marca, respondemos educada e formalmente e, se necessário, chamando para uma conversa privada (por email, inbox ou até ligação telefônica). Somente apagamos um comentário se ele violar as regras de conduta da página ou da própria rede social. Essa reação acontece somente em casos extremos: comentários racistas, machistas, xenofóbicos, pedófilos, etc. (E5).

E1 colabora destacando que não cabe ao social media dizer que o usuário está certo ou errado. "Nosso papel é sermos tolerantes e darmos respostas finas e elegantes como 'entendo 
o que você está dizendo, mas nós seguimos com a nossa posição'”. E1 também ressalta que é extremamente contra apagar comentários ou banir usuários, mas que essa ação pode acontecer quando aparecerem palavrões. "Colocou palavrão, perdeu a razão. Não posso manter uma relação com alguém a partir do momento que teve desrespeito. Logo, meu público não precisa ver um comentário assim".

A mesma atitude também é tomada por E6 e E7. "Eu leio, delibero (imaginando as razões que levaram a pessoa a escrever o que escreveu) e a ignoro", diz E6. Já E7 ressalta que se for um conteúdo que seja fácil identificar que a pessoa não sabe do que está falando, vale a pena esclarecer o fato. Contudo, se o usuário estiver comentando de forma negativa apenas por ser contra, o comentário é ignorado. E, ainda, se o conteúdo for algo muito pesado, ofendendo as pessoas, é imediatamente excluído.

Com relação a esses pontos, percebe-se que os profissionais que atuam diretamente com marcas e não com pessoas, partidos políticos e/ou governos (caso de E3 e E7), tendem a ser contrários a penas mais rígidas aos usuários, talvez, pelo fato de trabalharem com conteúdos menos propensos à disseminação do ódio, como cultura, moda e variedades.

De maneira geral, analisaram-se, também, as opiniões dos profissionais, sejam eles teóricos ou técnicos, a respeito das reações mais comuns dos profissionais da social media diante de comentários de ódio. Entre as reações que solicitamos que fossem comentadas estão: apagar o comentário, responder ao comentário e enfrentar o usuário, deixar com que os demais fãs da marca ou corporação entrem em atrito com o hater e banir usuário da página.

Neste tópico, convém ressaltar que uma das principais premissas para quem atua com redes sociais deve ser a interatividade com os usuários. Para Primo (2000), a interação acontece por meio da negociação em que engajam dois ou mais agentes ou, então, resume-se por meio do estímulo-resposta. $\mathrm{O}$ autor ainda destaca que é preciso lembrar que, em muitos relacionamentos, a comunicação não acontece, exclusivamente, por meio de um canal e cada usuário interage com seu contexto. Lemos (1997) ressalta as formas de influência na "relação com o mundo é uma relação interativa onde, à ações variadas correspondem retroações as mais diversas" (LEMOS, 1997, p. 1).

Talvez por prezarem, em primeiro lugar, pela interatividade com seus usuários, 57\% dos entrevistados desta pesquisa consideraram-se contra a prática de apagar comentários nas redes sociais. Segundo eles, esta ação deve acontecer apenas em casos extremos, como o uso de palavrões, citado por E1, ou, então, quando o comentário é publicado diversas vezes em um mesmo post como forma de chamar a atenção, conforme relatado por E5. Já E2 reforça que a rede social é um local que as pessoas usam para se comunicar e/ou se informar. "No momento que tu apagas um comentário, significa que estás privando a outra pessoa de participar daquela rede social", enfatiza. Por sua vez, E4 destaca que o social media precisa tentar resolver a questão direto com o usuário, seja para tentar entrar em contato, responder diretamente na crítica, fazer uma resposta padrão ou chamar a pessoa inbox, "Mas nunca deletar", reforça.

Já os demais entrevistados aceitam a ideia de apagar o comentário que incite o ódio. Conforme ressalta E3, se existe uma política de uso do espaço (página), e nela está previsto que é proibido incitar o ódio, é correto deletar. Para colaborar, E6 e E7 apresentam os mesmos pontos também ao concordar com a exclusão. Para eles, dependendo dos termos utilizados e da hostilidade da mensagem, o comentário deve ser apagado.

Outro tópico abordado durante a entrevista é a respeito da interação com o usuário que dissemina o ódio na página. Dos sete entrevistados, seis nos detalharam a importância de 
responder ao comentário e tentar resolver a situação da melhor forma. "É importante a marca responder e trabalhar junto com o usuário para tentar reverter a imagem ou deixá-lo mais tranquilo", responde E2. E5, por sua vez, sugere que, se o comentário for muito polêmico, o ideal é responder a ele pedindo uma forma de contato mais reservada.

Única entrevista não favorável à ideia de responder o comentário de ódio e enfrentar o usuário foi a de E3. Segundo ela, se o comentário infringe uma regra e a pena para isso é deletar o comentário, isso deverá ser feito, mas "nunca continuar o debate do assunto com ele, afinal já houve uma quebra de decoro entre as partes" (E3), conclui.

A mesma linha de respostas é seguida quando os entrevistados são questionados sobre deixar com que os demais fãs da marca entrem em atrito com o hater. Dos sete entrevistados, apenas E3 é contra, pois mais uma vez lembra que, se existem regras na página que punem o usuário com a exclusão do comentário, é isso que deve ser feito. "Não acho correto deixar os demais usuários rebaterem o ódio. Ideias, sim. Ódio, não", justifica.

Os demais entrevistados mostram-se favoráveis à ideia. E1 afirma que esta é uma opção muito interessante quando se tem um corpo de fãs muito bom. Contudo "é importante também que a marca entre em contato com o usuário". Para colaborar, E4 destaca o apontamento feito por E1 que fala que é importante, sim, a marca se posicionar mesmo que os fãs interfiram e respondam. E2 defende que essa ação (de deixar os usuários em contato com o hater) é perfeita e normalmente ocorre quando a marca trabalha bem nas redes sociais. Já E5 defende que essa ação é válida desde que não seja um caso em que é necessário apagar ou ocultar o comentário, porque "Não é papel de uma marca apaziguar brigas ou resolver atritos" (E5).

Quando apresentado como reação ao comentário de ódio o banimento do usuário da página, apenas a entrevistada 1 se diz extremamente contra a ação. Os demais entrevistados acreditam que, dependendo da situação, a ação pode ser válida. Essa é a linha defendida também por E2. De acordo com ela, se o social media já entrou em contato com a pessoa várias vezes, tentou fazer com que ela fizesse parte daquele sistema de uma forma civilizada e a pessoa não entendeu, a questão de banir o usuário não é tão prejudicial.

E3, por sua vez, ressalta que banir o usuário somente é uma alternativa se esta pena estiver prevista na política de uso da página, caso contrário, se a pena for deletar o comentário apenas, o usuário deverá ser mantido. A opção, de acordo com E5, E6 e E7 deve apenas ser considerada em casos extremos. Segundo E5, por exemplo, é preciso analisar bem cada uma das situações, pois banir pode ser um movimento que gere ainda mais barulho para o hater. Contudo "se for do entendimento de todos que aquele usuário só aparece para espalhar comentários de ódio, a alternativa passa a ser válida". Ainda sobre essa reação, E4 afirma que, durante todo o tempo que trabalha com mídias sociais, nunca aconteceu uma situação tão grave a ponto de o usuário ter de ser banido.

Como complemento ao tópico, E5 nos apontou mais uma ação válida em casos de disseminação de ódio nas páginas do Facebook. Segundo ela, denunciar usuários é uma opção disponibilizada na rede social e permitida tanto para perfis quanto para páginas. "As denúncias são ocultas, o que impede a marca de se expor para o hater e para sua base de fãs" (E5), justifica. As consequências ao usuário, no entanto, não são imediatas. O comportamento é analisado pela equipe do Facebook para, então, sofrer (ou não) punições que variam entre ser bloqueado por um tempo pequeno, médio ou longo da plataforma.

De acordo com a última categoria analítica, pode-se interpretar que E3 é a única a destacar a existência de uma política de uso da página, o que demonstra certa organização e políticas 
claras, semelhantes a um plano de contingência, que, de acordo com Luecke (2010, p. 61), os planos não podem ser criados e esquecidos, visto que as coisas mudam periodicamente. Além disso, o autor sugere que os planos sejam sempre testados em condições de simulados: "nunca presuma que um plano de contingência, idealizado no papel, realmente vá funcionar".

Dessa forma, pode-se observar que, apesar de os comentários que disseminem ódio e violência tenham surgido com maior frequência nas redes, os profissionais ainda não estão seguros com relação às atitudes que devem tomar diante dessas situações. Com isso, surge uma lacuna teórica que poderia servir para auxiliar esses profissionais, o que, infelizmente ainda não se confirma na literatura especializada em mídias sociais e comunicação na internet.

\section{CONSIDERAÇÕES FINAIS}

Durante este estudo, pôde-se perceber que, apesar da preocupação de gestores e analistas com o tema e com a velocidade com que os comentários que incitam o ódio são disseminados, os profissionais que atuam diretamente com mídias sociais, ainda não estão seguros com relação às atitudes que devem tomar diante de cada situação, em especial no que se refere à exclusão de comentários nas postagens. Tal insegurança também se deve ao fato de não ter, até o momento, nenhuma publicação especializada que trate de forma técnica e prática sobre o assunto. Além disso, também é possível destacar as diferenças entre os profissionais que atuam com marcas e aqueles que atuam nas áreas que tratam mais de políticas públicas e/ou governos. Durante as entrevistas, foram apresentados aos participantes quatro tipos de reações a comentários que incitem o ódio. No entanto, entre as respostas, não houve nenhuma unanimidade, o que corrobora com a análise acima de que ainda não há regras para a atuação do social media diante do discurso de ódio. Além de bibliografias especializadas, tal ponto poderia ser solucionado com a criação de políticas claras de uso das páginas, o que é citado apenas por um dos entrevistados durante a pesquisa.

Tópico quase unânime entre os entrevistados foi a respeito da interação com os usuários. Dos sete, seis detalharam a importância de manter o diálogo com o objetivo de tentar resolver ou, até mesmo, minimizar a situação. Outro ponto importante e que merece destaque é a respeito dos conteúdos mais propensos a comentários que incitam o ódio e a violência. De acordo com os entrevistados, os temas mais sensíveis de serem tratados são os que abordam política, religião, animais, gêneros e raça. Por serem estes os temas mais suscetíveis, os profissionais que atuam diretamente com questões ligadas a eles, tendem a ser favoráveis a penas mais rígidas aos usuários que disseminam o ódio.

Além disso, convém ressaltar que, tanto o planejamento quanto a criação dos conteúdos que serão publicados nas redes sociais, passam pelo entendimento do público da página. Tão importante quanto à postagem do conteúdo, é entender com quem se está falando e quais são seus principais interesses. Dessa forma, o risco de ser alvo de comentários negativos tende a ser menor.

O que está proposto aqui pode, futuramente, tornar-se um novo objeto de estudo, pelo qual a análise poderá ser ampliada, cruzando as reações dos profissionais que atuam com marcas (empresas) com as dos profissionais que atuam no meio político, trabalhando com governos ou pessoas. Assim, poder-se-á traçar um paralelo com as principais diferenças de atuação, tendo em vista que as reações dos usuários perante os conteúdos e páginas também são diferentes, propondo diretrizes de comportamento para esse ambiente tão volátil que é a rede social. 0 
mesmo usuário que faz um comentário que incita o ódio em uma página com cunho político, talvez não o faça em uma página que trate de gastronomia, por exemplo.

\section{REFERÊNCIAS}

AMARAL, A.; MONTEIRO, C. "Esses Roquero não curte": performance de gosto e fãs de música no Unidos Contra o Rock do Facebook. Revista FAMECOS, Porto Alegre, v. 20, n. 2, p. 446-71, maio/ago. 2013.

BARDIN, L. Análise de conteúdo. Tradução de L. de A. Rego e A. Pinheiro. Lisboa: Edições 70, 2006.

CASTELLS, Manuel. Redes de indignação e esperança: movimentos sociais na era da internet. Rio de Janeiro: Jorge Zahar, 2013.

. A sociedade em rede - a era da informação. 15. ed. São Paulo: Paz e Terra, 2012. v. 1.

. Comunicació i poder. Barcelona: UOC Editorial, 2009.

Comunicação, poder e contra-poder na sociedade em rede. Jornal Internacional de Comunicação, v. 1, n. 1, p. 29, 2007.

CHIZZOTTI, A. Pesquisa em ciências humanas e sociais. 8. ed. São Paulo: Cortez, 2006.

CRESWELL, J. W. Projeto de pesquisa: métodos qualitativo, quantitativo e misto. 2. ed. Tradução de L. de O. Rocha. Porto Alegre: Artmed, 2007.

DAHLGREN, P. The internet, public spheres and political communication: dispersion and deliberation. Political Communication, New York, v. 22, n. 2, p. 147-62, 2005.

DEGENNE, A.; FORSÉ, M. Les réseaux sociaux: une analyse structurale en sociologie. Paris: Henri Mendras, 1994.

ECO, Umberto. Número zero. Rio de Janeiro: Record, 2015.

ERICKSON, F. Métodos cualitativos de investigación. In: WITTROCK, M. C. La investigación de la ensenanza, II. Barcelona/Buenos Aires/Mexico: Paidos, 1989. p. 195-299.

FENTON, Natalie. The Internet and Radical Politics In: CURRAN, J.; FENTON, N.; FREEDMAN, D. Misundestanding the internet. New York: Routledge, 2012.

FISS, Owen M. A ironia da liberdade de expressão: estado, regulação e diversidade na esfera pública. Rio de Janeiro: Renovar, 2005.

GASKELL, George. "Entrevistas individuais e grupais". In: BAUER, Martin; GASKELL, George (Org.). Pesquisa qualitativa com texto, imagem e som: um manual prático. 2. ed. Tradução de Pedrinho Guareschi. Petrópolis, RJ: Vozes, 2003. p. 64-89.

GIL, A. C. Como elaborar projetos de pesquisa. 3. ed. São Paulo: Atlas, 2006.

GOFFMANN, E. Estigma: notas sobre a manipulação da identidade deteriorada. 4. ed. Rio de Janeiro: LTC, 2008.

GOSCIOLA, Vicente. Roteiro para as novas mídias. Do cinema às mídias interativas. São Paulo: Senac, 2003. HONNETH, Axel. Luta por reconhecimento: a gramática moral dos conflitos sociais. São Paulo: Editora 34, 2003.

JENKINS, Henry. Cultura da convergência. São Paulo: Aleph, 2009.

LATOUR, Bruno. Reagregando o social: uma introdução à Teoria do Ator-Rede. Salvador: Edufba; Bauru, SP: Edusc, 2012.

. Jamais fomos modernos: ensaio de antropologia simétrica. 2. ed. São Paulo: Editora 34, 2009.

LEÃO, Lucia. O labirinto da hipermídia: arquitetura e navegação no ciberespaço. 2. ed. São Paulo: Iluminuras/FAPESP, 2001. 
LE BON, Gustave. Psicologia das multidões. [S.I.]: Mem-Martins, Europa América, 1895. Título original "La Psychologie des Foules".

LEBRUN, J. P. O futuro do ódio. Porto Alegre: CMC, 2008.

LEMOS, André. Espaço, mídia locativa e teoria ator-rede. Galáxia, São Paulo, v. 13, n. 25, p. 52-68, 2013.

Anjos interativos e retribalização do mundo: sobre interfaces digitais. 1997. Disponível em: <http:// www.facom.ufba.br/ciberpesquisa/lemos/interativo.pdf>. Acesso em: 2 jun. 2016.

LUECKE, Richard. Gerenciando a crise. Rio de Janeiro: Record, 2010.

MALINI, Fábio; ANTOUN, Henrique. A internet e a rua: ciberativismo e mobilização nas redes sociais. Porto Alegre: Sulina, 2013.

MARTELETO, Regina Maria. Análise de redes sociais: aplicação nos estudos de transferência da informação. Ciência da informação, v. 30, n. 1, p. 71-81, 2001.

MEYER-PFLUG, Samantha Ribeiro. Liberdade de expressão e discurso do ódio. São Paulo: Revista dos Tribunais, 2009.

MOCELLIM, Alan. Lugares, não-lugares, lugares virtuais. Em Tese, Florianópolis, v. 6, n. 3, p. 77-101, jan./ jul. 2009.

OSTROWER, Fayga. Criatividade e processos de criação. Petrópolis, RJ: Vozes, 1978.

PEREIRA, Gustavo. Os 3 estágios das mídias sociais. Porto Alegre: Dinamize, 2011.

PRIMO, Alex. Interação mediada por computador: comunicação, cibercultura, cognição. Porto Alegre: Sulina, 2007.

. Interação mútua e reativa: uma proposta de estudo. Revista da Famecos, n. 12, p. 81-92, jun. 2000. Disponível em: <http://www.ufrgs.br/limc/PDFs/int_mutua_reativa.pdf>. Acesso em: 12 maio 2016.

RECUERO, Raquel. A conversação em rede: comunicação mediada pelo computador e redes sociais na internet. Porto Alegre: Sulina, 2012.

. Redes sociais na internet. Porto Alegre: Sulina, 2009.

SALAVERRÍA, Ramón; NEGREDO, Samuel. Periodismo integrado. Convergencia de medios y reorganización de redacciones. Barcelona: Editorial Sol90, 2008.

SOLOVE, Daniel J. O futuro da reputação: fofocas, rumor, e privacidade na internet. New Haven, Connecticut, EUA: Yale University Press, 2007.

TEIXEIRA, Patrícia Brito. Caiu na rede. E agora? Gestão e gerenciamento de crises nas redes sociais. Digitaliza Conteúdo, 2013.

Sociedade do risco na sociedade da informação: gestão e gerenciamento de crise nas redes sociais. In: CONGRESSO CIENTÍFICO BRASILEIRO DE COMUNICAÇÃO ORGANIZACIONAL E DE RELAÇÕES PÚBLICAS (ABRAPCORP), 5., 5-7 maio 2011, São Paulo. Anais... São Paulo: Editora Schoba, 2011. Disponível em <http://www.abrapcorp.org.br/anais2011/trabalhos/trabalho_patricia.pdf>. Acesso em: 15 maio 2016.

VASCONCELOS, Luciene Ricciotti. Planejamento de comunicação integrada: manual de sobrevivência para as organizações do século XXI. São Paulo: Summus Editorial, 2009.

WOLTON, Dominique. Informar não é comunicar. Porto Alegre: Sulina, 2010.

YIN, Robert K. Estudo de caso - planejamento e métodos. 2. ed. Porto Alegre: Bookman, 2001.

\section{Sobre as autoras:}

Marluci Stein: Graduada em Comunicação Social - Habilitação em Jornalismo, com ênfase em Gestão da Comunicação, Especialista em Comunicação Estratégica e em Marketing. E-mail: marlucistein@gmail.com 
Cristine Hermann Nodari: Pós-Doutorado em Inovação pelo Programa Nacional de PósDoutorado da Coordenação de Aperfeiçoamento de Pessoal de Nível Superior (PNPD/ CAPES). Doutora em Administração pela Pontifícia Universidade Católica do Rio Grande do Sul (PUCRS) e pela Universidade de Caxias do Sul (UCS), Bolsista do Programa de Suporte à Pós-Graduação de Instituições de Ensino Particulares da Coordenação de Aperfeiçoamento de Pessoal de Nível Superior (PROSUP/CAPES). Mestre em Administração pela Universidade de Caxias do Sul (UCS). Especialista em Gestão Empresarial pela Fundação Getúlio Vargas (FGV). Graduação em Administração pela Universidade do Vale do Rio dos Sinos (UNISINOS). E-mail: cristine.nodari@gmail.com

Julice Salvagni: Pós-Doutora, Programa Nacional de Pós-Doutorado da Coordenação de Aperfeiçoamento de Pessoal de Nível Superior (PNPD/CAPES). Doutora em Sociologia (UFRGS/ CAPES). Mestre em Ciências Sociais (Unisinos), Especialista em Gestão Empreendedora (FTEC) e Psicóloga (Unisinos). E-mail: julicesalvagni@gmail.com 
